M. Braun-Unkhoff, U. Riedel

Alternative Fuels In Aviation

CEAS Aeronautical Journal 6 (1), 83-93, 2015.

The original publication is available at www.springerlink.com

http://dx.doi.org/10.1007/s13272-014-0131-2 


\title{
Alternative Fuels In Aviation
}

\author{
Marina Braun-Unkhoff*, Uwe Riedel \\ Institute of Combustion Technology, German Aerospace Center (DLR) \\ Pfaffenwaldring 38-40, 70569 Stuttgart, Germany
}

*: Corresponding author: marina.braun-unkhoff@dlr.de, phone: +49-711-6862-508 ; fax: +49-711-6862-578

\begin{abstract}
During the last years, the aviation sector has been looking into alternatives to kerosene from crude oil, to combat climate change by reduction of greenhouse gas (GHG) emissions and to ensure security of supply at affordable prices. The efforts are also a reaction to commitments and policy packages. Currently, a wide range of possible fuel candidates and fuel blends are discussed in the triple feedstock, process, and product. Any (synthetic) aviation fuel must be certified; hence, a profound knowledge on its properties, in particular thermophysical and chemical, is inevitable. In the present paper, an overview is given on alternative jet fuels, looking into the short-term and long-term perspective. Examples focusing on experimental and modeling work of combustion properties of existing - CtL (Coal to liquid), GtL (Gas to liquid) - and possible alternative fuels $\mathrm{GtL}+20 \%$ 1-hexanol, GtL+50\% naphthenic cut - are presented. Ignition delay times and laminar flame speeds were measured for different alternative aviation fuels over a range of temperatures, pressures, and fuel-air ratios. The data are used for the validation of a detailed chemical reaction mechanism following the concept of a surrogate. Such validated reaction models able to describe and to predict reliably important combustion properties of jet fuels are needed to further promote the development of even more sophisticated jet engines and to optimize synthetic jet fuel mixtures in practical combustors.
\end{abstract}

Keywords Alternative Aviation Fuels - Combustion Reaction Mechanism - Ignition - Laminar Flame Speed

\section{Introduction}

Fossil fuels are currently the primary energy source worldwide [1]. Presently, kerosene from crude-oil is the only jet fuel worldwide available for decades [2-3]. The total consumption of jet fuel was about 6.8 million barrels per day in 2007 [4]. Today, jet fuels constitute about 6 percent of the global oil consumption: for example, in 2011, the aviation industry produced 669 million tons of carbon dioxide $\left(\mathrm{CO}_{2}\right)$ [5], about $2 \%$ of total anthropogenic $\mathrm{CO}_{2}$ emissions worldwide [6]. A further increase of the air traffic is foreseen, by about 3-5\% per year for passengers and $9-10 \%$ for cargo flights over the next 20 years [7]. If fuel consumption and hence $\mathrm{CO}_{2}$ emissions will continue to grow at the same rate, then, in 2050, the $\mathrm{CO}_{2}$ emissions would be almost six times higher than today (Fig. 1). Only the use of so called low carbon fuels - fuels from biomass - will lead to a reduction of $\mathrm{CO}_{2}$ emissions.

During the last decades, alternative energy resources became increasingly important [9], mainly to combat global warming as well as to ensure security of supply and a lower increase of costs by reducing fuel import dependency. The share of fuel costs within an airliner's budget has risen to more than 33\% in 2012 [10]. As a response, the commercial aviation sector is looking for alternative fuels, as blends or full substitution to kerosene, with a priority to renewable fuels [11-13].

The aviation initiative for renewable energy in Germany (aireg) started in June 2011 as a platform for promoting sustainable jet fuel development [11]. IATA, the International Air Transport Association, has committed their vision of carbon neutral growth starting 2020 and to halve emissions by 2050 compared to 2005 levels [12]. Actually, improvements in technology, air traffic management (ATM) and operations will lead to a sizable emissions reduction. However, as seen in Fig. 1, aviation industry's ambitious goals can only be met with a significant contribution of low carbon alternative fuels. ACARE, the Advisory Council for Aeronautical Research in Europe, has set the goal of reducing $\mathrm{CO}_{2}$ emissions by $50 \%$ in 2050 compared to 2005 [7]. In the U.S., several initiatives are ongoing, e.g. the "Commercial Aviation Alternative Fuels Initiative” (CAAFI) [13].

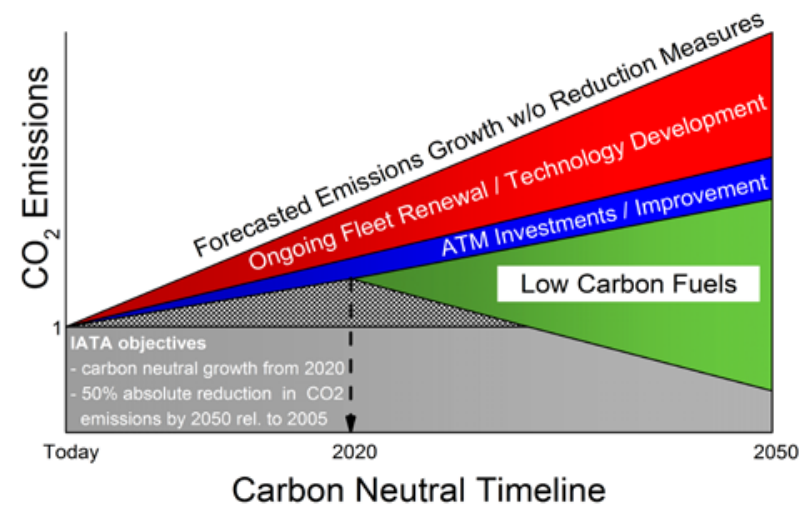

Fig. 1: Key drives of $\mathrm{CO}_{2}$ emissions reduction in aviation [8] 
The search for alternative fuels is also motivated by policy demands. In the EU (European Union), the aviation sector is embedded in the EU policy package concerning renewable energy and $\mathrm{CO}_{2}$ emissions. In 2011, the European Advanced Biofuels Flight Path was launched by the EU as an industry wide initiative to speed up the commercialization of aviation biofuel deployment in Europe [14]. A roadmap was defined with clear milestones to achieve biofuel sustainably produced in the EU, with an annual production of two million tons, and to integrate into the EU civil aviation sector by 2020.

Sustainability in energy supplies may require new concepts with respect to feedstock, production, and final product. To enable a well-founded assessment on newly produced aviation fuels, life-cycle analysis taking into account also effects of iLUC (indirect land use change) are needed [15-16]. Moreover, it must be guaranteed that no competition between food, feed, and fuel exists. A sustainable aviation fuel will have lower emissions of $\mathrm{CO}_{2}$, besides further desirable advantages, such as no sulfur emissions and a lesser amount of other pollutants such as NOx, unburned hydrocarbons, and soot particles. However, a key for the success of the introduction of alternative aviation fuels is their availability at acceptable prices in sufficient amounts and their suitability, with no modifications needed in today's aviation infrastructure, following the idea of a drop-in fuel.

Introducing new jet fuels in aeronautics is a great challenge, in particular with respect to the technical requirements: Aircraft needs are very strict and specific, with more severe constraints (e.g. freezing point, energy density, flash point, flammability limit, amount of aromatics) compared to any other transportation means. Hence, any aviation fuel must be characterized and certified [17], with respect to its physical and chemical properties, to ensure a safe and reliable operation for the whole flight envelope. A further restriction is to prove that any newly developed alternative aviation fuel is fully compatible with today's airframe components and aeroengines, due to their long lifetime cycle. Also, to avoid any additional costs, no change in the present infrastructure - fuel logistic, airport - must be ensured.

Hence, it is of outmost importance to expand our knowledge on renewable jet fuels not only with respect to the experimental characterization of the fuel but also with respect to modeling capabilities enabling predictive computational fluid dynamics simulations. Detailed knowledge of major combustion properties is inevitable, for the relevant pressure, temperature, and fuel air regime, to enable a highly reliable and safe operation, with influencing the environment as little as possible.

In the present paper, an overview will be given on current alternative jet fuels, looking into the short-term and long-term perspective. Then, examples focusing on experimental and modeling work of combustion properties of existing and possible alternative fuels will be presented. The work was mainly performed within national and international projects: burn-FAIR [18] ALFA-BIRD [15],
SWAFEA [16], and GtL-QSTP (Qatar Science and Technology Park) [19].

Each of these programs was addressing specific questions. Within ALFA-BIRD, the focus was on the selection and the evaluation of the most promising alternative fuels with short to long-term perspective. SWAFEA provided recommendations and a roadmap to policy makers by taking into account technical, environmental, and economical aspects. The German project burn-FAIR was dedicated to provide data for durability and long-term effects when operating scheduled flights. The GtL jet fuel research consortium led by QSTP started the approach of varying fuel formulation and looking at fuel properties and combustion performance.

\section{Alternative aviation fuels}

Two points need to be addressed: Any aviation fuel must be certified, mostly for safety reasons, and any newly developed alternative aviation fuel must be compatible (drop-in fuel) or almost compatible (near drop-in fuel) to today's aircrafts, mostly for costs reasons. Only those alternative fuels will be viable, whose properties are at least as good as those of Jet A-1.

Usually, when developing and introducing a new synthetic aviation fuel, the typical sequence is as follows: (i) first, the feedstock is identified, (ii) then, the production process, (iii) characterization of the fuel by fit for-purpose tests, (iv) approval process, (v) demo-flight, (vi) certification, and (vii) scheduled commercial flight.

\subsection{Overview}

Any aviation fuel - whether Jet A-1 (kerosene from crude oil) or an alternative jet fuel - must be certified, to ensure a safe and reliable operation for the whole flight envelope. Thus, the aviation fuel will perform appropriate with respect to the combustion in the aero engine and to the whole fueling system including material (sealings) and thermo stability aspects of the fuel itself. The two specifications primarily used worldwide are ASTM D1655-09 [17] and Def Stan 91-91 [20].

Today, the technical feasibility of alternative jet fuels is proven. Over the last years, several demonstrations and commercial flights on up to $50 \%$ alternative fuels and engine demonstrations with alternative fuels have been carried out nearly in every continent; see the overview in [21-23]. Presently, a large variety of feedstock, processes, and resulting products (alternative jet fuel) are discussed; see e.g. [14, 21-23]. However, sustainable alternative aviation fuels are currently not available in sufficient amounts, as e.g. pointed out in the SWAFEA study [16].

Synthetic fuels can be obtained from fossil (coal, gas) and renewable sources (waste, biomass) by five pathways: via (i) gasification applying the Fischer-Tropsch (FT) process; (ii) liquefaction or pyrolysis; (iii) biological or chemical pathways; (iv) hydrolysis and/or fermentation; and (v) hydrogenolysis and esterification, once oil is 
extracted (Fig. 2). For the midterm range, synthetic paraffinic kerosenes (SPK) from FT-process or hydro treatment blended in Jet A-1 seem to be the most promising alternative. In this context, BtL (biomass to liquid), HRJ (hydrogenated renewable jet), and HEFA (hydro processed esters and fatty acids) are the only ones to provide substantial progress regarding sustainability and $\mathrm{CO}_{2}$ emissions. In addition, future candidates to jet fuel could be, after hydro processed, new plant (or vegetable) oils or fatty acids, blended with kerosene. Kerosene and very high-quality diesel can be obtained by subsequent hydrocracking of vegetable oil; industrial hydrogenation plants are under construction [24-25]. An interesting feature of modern hydrogenation processes is the possibility of influencing the length of the carbon chain (short or long molecules) as well as the chemical family of the products (branched or long-chained paraffins). This has an important influence on the physical properties of the resulting products such as cetane index and cold flow properties. Quite recently, producing synthetic jet fuels from sugar seem to be a low-cost alternative to the FT-process which has high investment costs [13-14]. These renewable synthetic jet fuels known as alcohol to jet (ATJ) and sugar to jet (STJ) are expected to be certified by ASTM in the near future. Thus, these additional new sustainable aviation fuels could provide additional answers to the bottleneck-type issues of biomass availability and economic feasibility of scalingup the production capabilities.

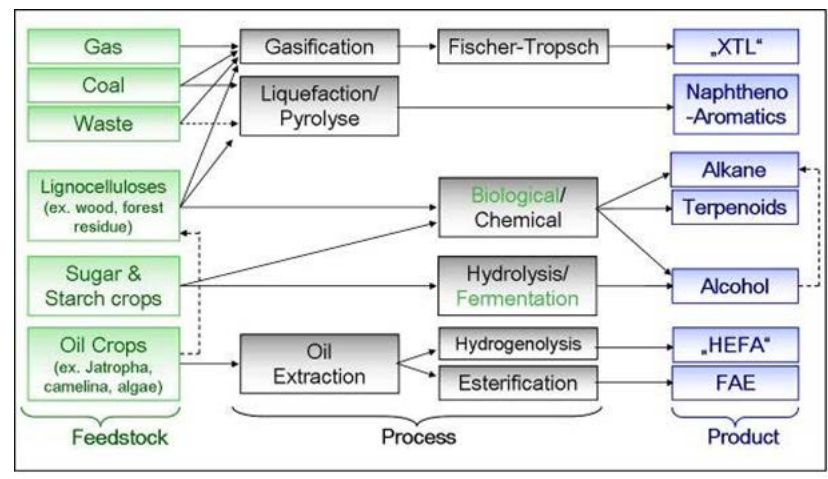

Fig. 2: Summary of presently known alternative fuel pathways. "XTL": Anything to liquid; "HEFA": Hydro processed esters and fatty acids; "FAE": Fatty acid esters

The fuel readiness level (FRL) introduced by CAAFI [13] is a measure for the technical feasibility of a particular fuel to serve as an aviation fuel by assessing fuel quality from the certification, following the approval process. As one can see from Fig. 3, this procedure needs up to a million of liters of the fuel to be approved.

The first alternative jet fuel having been approved for commercial aviation was a CtL (coal to liquid), developed by SASOL: first, a semi synthetic jet fuel (SSJF) was approved in 1998, followed by a fully synthetic jet fuel
(FSJF) in 2008 [26]. Then, the generic approval and certification of Fischer Tropsch fuels (FT-fuels), also called FT-SPK fuels, was set up in 2009, by the release of standard practices for qualification and approval of new aviation turbine fuels and fuel additives (ASTM D4054), and the standard specification for aviation turbine fuels containing synthesized hydrocarbons (ASTM D7566). A GtL (gas to liquid) fuel was developed [27]. Regarding BtL-fuels (biomass to liquid), potential feedstock can be biomass or biomass by-products, waste, algae, or yeast, for example. The bio-based alternative fuel HEFA was approved in July 2011, as the revised release of the ASTM D7566 Standard includes hydro processed esters and fatty acids (HEFA). Please note that FT-SPK and HEFA are certified as aviation jet fuel up to an amount of $50 \%$ in blends of kerosene from crude-oil.

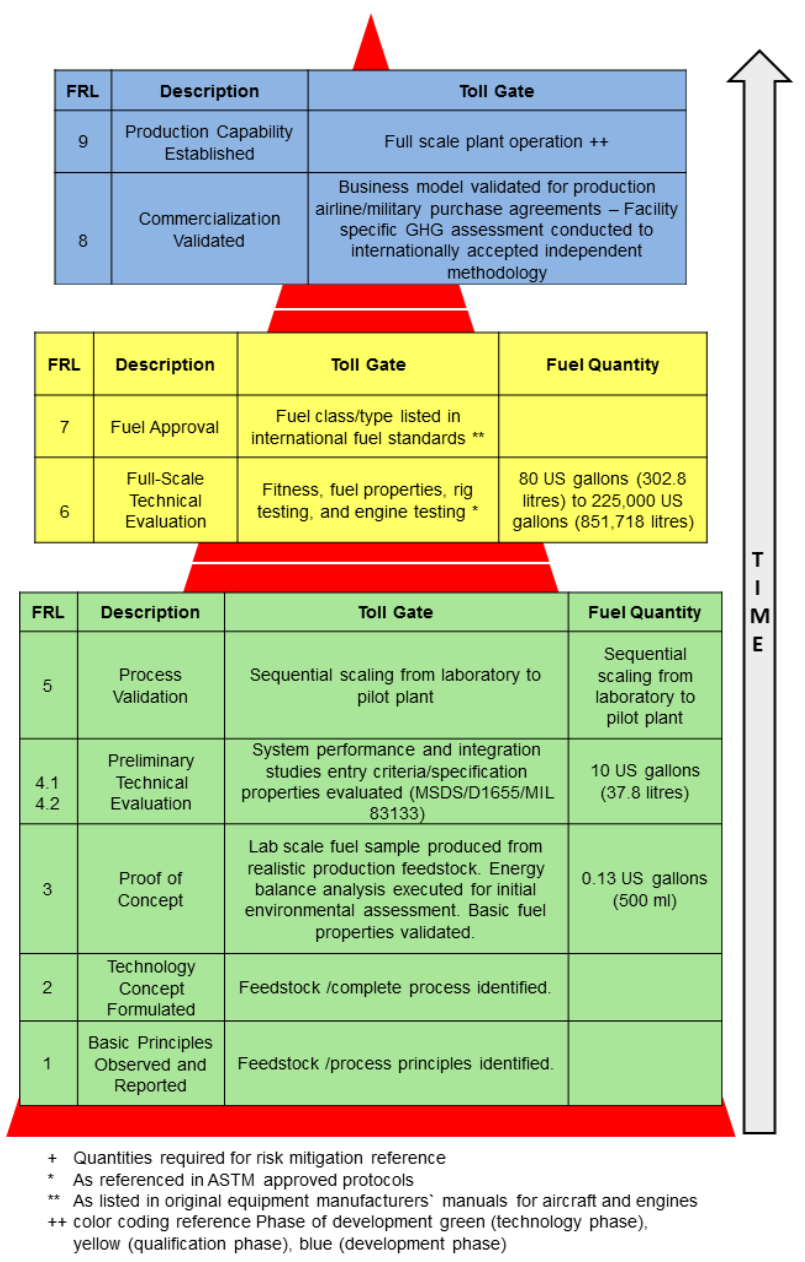

Fig. 3: The Fuel Readiness Level (FRL) - Alternative Jet Fuels [13]. R\&D phase: green; certification \& qualification phase: yellow; business phase: blue

The first commercial flights performed were with a CtL in 1998 [26], with a GtL fuel in 2009 [27], and with a HEFA in 2011 [18]. Lufthansa has performed the first scheduled commercial flights worldwide operated between Hamburg and Frankfurt for several months, with 
a bio-derived alternative fuel (50\% blend to crude oil kerosene) in one of the two engines of an airbus A321 [18]. Measurements of the emission characteristics have proven that the synthetic fuel was at least as good as the kerosene from crude oil $[18,28]$.

\subsection{Composition}

Kerosene from crude oil (Jet A-1) is the only jet fuel worldwide in use. There is no single kerosene: The detailed composition is varying as a function of season and location. Typically, kerosene consists of a large variety of different species belonging to four chemical families: (i) long-chained unbranched alkanes ( $n$-alkanes), (ii) long-chained, branched alkanes (iso-alkanes) (iii) cyclic alkanes (naphthenes) and (iv) aromatics (Fig. 4). Furthermore, small amounts of additives and metal deactivators are present [29].

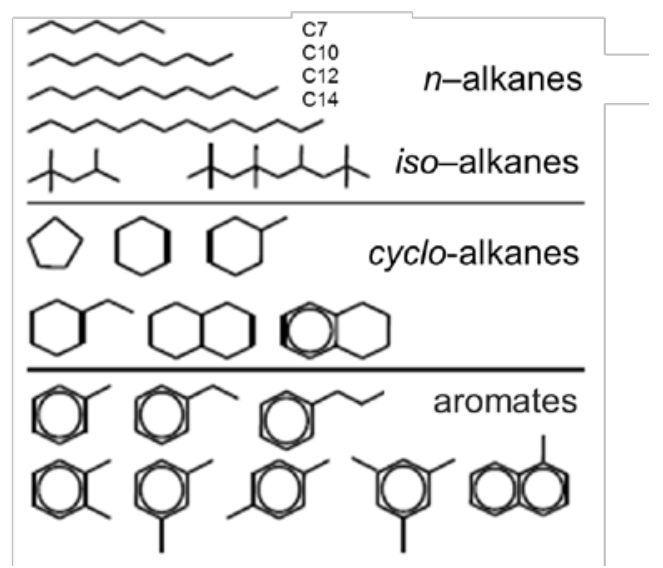

Fig. 4: Chemical families present in Jet A-1

The composition of alternative aviation fuels is similar to the one of Jet A-1 in the sense that they are also composed of hydrocarbons. However, the amount, the length of hydrocarbons and their chemical family might differ considerably. The composition of each fuel can be analyzed and identified by a combined GC/MS analysis (gas chromatography / mass spectrometry); a gas chromatogram can be considered as a finger-print of a specific fuel. Typical examples of gas chromatograms of approved jet fuels (petroleum, FT, HEFA, and near future candidates: alcohol oligomerization and direct fermentation) are given by CAAFI 2009 [13]. GtL is a mixture of only three chemical families, without any aromatics present (Fig. 4).

In the past, the jet engine fuel has been developed as a whole, focusing on safety and performance within the entire flight envelope. The kerosene cut from oil refineries was optimized to meet turbine fuel specifications, which were also developed in parallel. Therefore, no comprehensive knowledge has been achieved with respect to how certain families of compounds or single species within Jet A-1 might affect specific properties (chemical and physical) of the fuel and what might be their impact on engine performance and emissions, the aircraft systems, or ground handling and safety. The only exception was the development of very few approved additives, for example reduce fouling tendencies.

Now, with the production and existence of several alternative jet fuels of a composition significantly different to the one of Jet A-1, the question is open how the chemical nature of the fuel will affect its performance and its suitability. First, their combustion needs to be investigated, in particular, ignition, flame speed, and emission pattern (pollutants). Secondly, the effect of several individual compounds needs to be carefully investigated to exclude any misbehaving with respect to performance and safety issues. Within this context, the role of aromatics naturally occurring in kerosene stemming from crude oil must be considered due to its accepted critical role in safety (sealing issues) as reported recently [30] although no comprehensive investigation addressing this issue was performed in the past. Of course, the physical properties of a fuel is depending on its specific composition, so investigations and tests need to be performed to guarantee that the fuel considered is fulfilling the fuel specifications.

\subsection{Technical needs and properties}

Only a certified fuel is allowed to be used for commercial scheduled flights. The kerosene-type of fuel used in aeronautics is not solely the energy carrier but is also a major component in heat exchange and weight balance, all of this under very extreme conditions ranging from ground to high altitude.

For these reasons, kerosene is the only practical fuel produced under very strict physical standards (energy content, freezing point, boiling point, viscosity, polarity, surface tension, minimum ignition temperature etc.) in order to cope with the demands of civil and military aviation. Some fuel properties are very restrictive; for example, the freezing point has to be below $-47^{\circ} \mathrm{C}$ in order to keep high altitude flight capability, the thermal stability sufficiently must be high in order to preserve engine cooling capability; or the energy density will tailor the aircraft mission range: for example, the specific energy density impacts the aircraft take-off weight and the volumetric density has impacts on aircraft size or range.

Synthetic kerosene although it must comply with the Jet A-1 specifications might have a specific combination of physical properties that would substantially affect elementary processes occurring in a gas-turbine combustor. This could lead to a detrimental modification in the performance of these modern combustors.

For instance, recent experimental investigations concerning the combustion of FT-synthetic jet fuels [31] in gas turbines have shown very similar NOx and CO emissions when compared to their crude-oil-based counter-part. However, when it comes to soot formation larger differences depending on the nature of the fuel are 
expected; for example, a GtL fuel is free of aromatic compounds which have a high sooting propensity, thus using a GtL-fuel offers the chance for an improved local air quality, see Fig. 5 . It should be mentioned that the sooting behavior of alternative fuels has been addressed within the ALFA-BIRD study, at Toronto University.

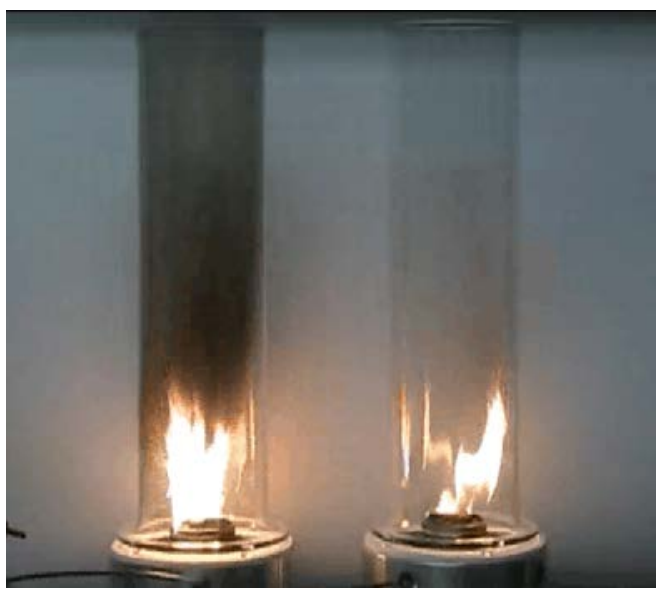

Fig. 5: Burning of a GtL (right) and of Jet A-1 (left) showing clearly the lower sooting propensity of a GtL fuel [32]

A profound knowledge is needed, with respect to chemical, physical, and thermo physical fuel properties and to the combustion process occurring in the combustor. The fuel is burnt under highly turbulent conditions, with mixing of air and fuel at several points in an inhomogeneous flow field in the gas turbine. The temperature differs depending on the flame position in the combustor: close to the fuel's injection or near the combustor's walls or exit. The temperature has a large effect on the amount of pollutants, in particular of NOx and soot particles.

\subsection{Methodology to characterize the combustion behaviour}

Today, numerical simulations able to take into account the interactions between heat release and turbulent flow are run to understand in more detail what is occurring in the combustion under highly turbulent conditions. In order to do so, chemical kinetic reaction models validated by relevant experiments are one of the essentials among a variety of models and methods used in Computational Fluid Dynamics (CFD) simulations (Fig. 6).

A detailed reaction model is needed to be predictive with respect to major combustion properties e.g. heat release, ignition behavior, and pollutant formation. Thus, the need for running experiments with a particular fuel and for specific parameters (temperature, pressure, fuelair ratio) can be reduced, saving time, and costs. In some cases, numerical simulations offer the only way to study in detail the influence of a fuel or of specific fuel components on temperature distribution, flow field, and pollutant formation in a gas turbine, for different parameters.

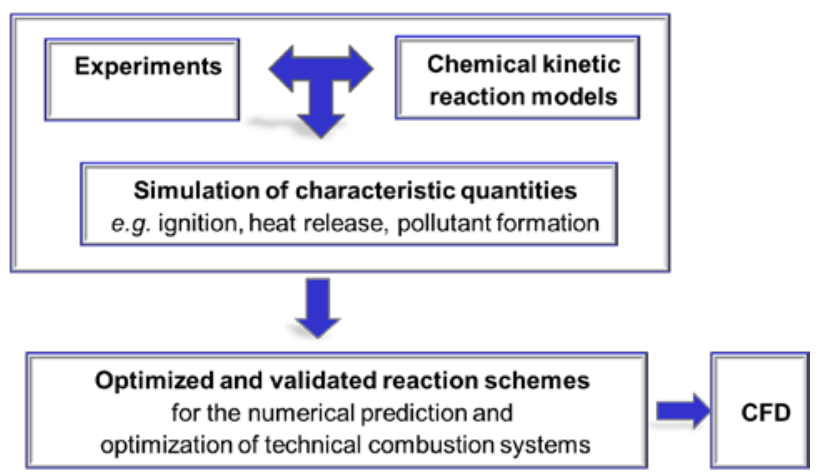

Fig. 6: Typical workflow of validating reaction schemes to be used in CFD calculations by relevant experiments

The chemical kinetic modelling of the oxidation of kerosene - whether a conventional, from crude oil, or a synthetic one - is a challenging task due to the hundreds of different species kerosene is composed of. Thus, it is not possible to develop a detailed reaction model by including each of the species and all of the reactions that may occur between them and their oxidation intermediates including radicals and products. Therefore, the combustion of kerosene is modeled by introducing so-called surrogates or model fuels. A surrogate is composed of a few hydrocarbons selected from the different chemical families, which represent the major components and their fraction in a given fuel. A surrogate can be built such that it will have physical and chemical properties similar to those of the real jet fuel. Several formulas for a surrogate exist, with - depending on the objective - about 3-7 fuel components present, to describe the combustion properties of practical blends, see e.g. [2, 29, 33-39].

Concerning the technical suitability of a fuel, the elaborated detailed kinetic reaction mechanism of a specific surrogate should be able to describe reliably heat release, ignition behavior, and pollutant formation in practical combustion chambers, for the relevant range of combustion parameters, such as stoichiometric ratio, temperature, and pressure. Such surrogates are of high interest since they allow studying the effect of chemical composition and fuel properties on the combustion.

Numerous investigations were carried out for providing the knowledge needed, focusing on main combustion properties and emission tests (see e.g. [21-22, 29, 33-36, 40-42]). Also, several investigations were done in order to establish a surrogate and a detailed reaction model for predicting combustion properties [2, 21-22, 29, 33-36, 37-39]. Attention is also drawn to evaluate models able to match thermo physical properties of kerosene, such as density or distillation curve [37-39, 43]. 


\section{Combustion properties of alternative aviation fuels}

Basic combustion characteristics must be known reliably over a relevant parameter range (temperature, pressures fuel composition, and fuel-air ratio) before any detailed or optimized design of a system can be done, such as the design of a combustion chamber using CFD simulations. This knowledge allows avoiding operating conditions where flashback or self-ignition may cause a severe damage of the burner and the combustion chamber.

Two of the most important fundamental combustion properties of any fuel are laminar flame speed, as a means for describing heat release, and ignition delay time.

The laminar flame speed has a direct impact on the flame length: depending on, the flame will stabilize at different distances from the combustor inlet. In addition, if the laminar flame speed of an alternative fuel would differ too much from the one of Jet A-1, the heat load of the walls or recirculation zones might change, in a technical system. The risk of a blowout is increased for low flame speeds at relatively high gas velocities, the risk of a flashback in premixed systems for high flame speeds. In summary, a reliable knowledge of the values for the laminar flame speed is of fundamental interest, for safety reasons and to avoid any damage to the jet turbine.

The ignition delay time is an indicator for the stability of combustion. The knowledge on ignition delay times allows a better estimation of the risk of flashback or autoignition occurrence. Very low ignition delay times increase the risk of a flashback in a premixed system. With very high ignition delay times, ignition or re-igniting of the fuel might be impossible; in addition, unburned gas might exit the hot reaction zone resulting in an increased amount of unburned hydrocarbons (UHC) in the exhaust gas.

In the present work, results on the characterization of these two major combustion properties of four reformulated fuel-air mixtures - as well as for standard kerosene, for comparison [16] - are discussed: (i) laminar flame speeds measured using the cone angle method and (ii) ignition delay times measured in a high pressure shock tube [15, 22, 34-36,44-45].

These data are compared with data predicted by a detailed reaction model consisting of 2185 species and 8217 reactions [15, 34-36, 44-46] following the concept of a surrogate as discussed above. More detailed information of the reaction model is given in [44-45].

\subsection{Selected fundamental properties}

In Tab. 1, the formulation of alternative fuel mixtures considered within several projects are summarized. In the present work, examples will be given focusing on the fuels investigated within the EU project ALFA-BIRD.

In Tab. 2, selected fundamental properties of the reformulated alternative fuel mixtures are given, including those of Jet A- 1 . The composition of the fuel blends is selected such that their properties are comparable to the ones of Jet A-1 fuel, thus fulfilling the criteria of a "dropin" fuel. This is also true for the addition of hexanol, a long-chained alcohol currently not allowed in a certified jet fuel due to the presence of oxygen. Almost no energy penalty exists; note that potential material compatibility and sealing issues were studied within ALFA-BIRD.

Table 1: Alternative fuels investigated within several projects; NaAr: naphtheno aromatics; *: blended

\begin{tabular}{|c|c|c|c|c|c|c|c|c|}
\hline Fuel & Jet A-1 & CtL & GtL & BtL & $\begin{array}{c}\text { alcohol } \\
*\end{array}$ & $\begin{array}{c}\text { HVO } \\
*\end{array}$ & FAE & NaAr \\
project & & & & & & & \\
\hline alfa-bird & & $\mathrm{x}$ & $\mathrm{x}$ & & $\mathrm{x}$ & $\mathrm{x}$ & & $\mathrm{x}$ \\
\hline swafea & $\mathrm{x}$ & & & & & $\mathrm{x}$ & $\mathrm{x}$ & $\mathrm{x}$ \\
\hline QSTP & & & $\mathrm{x}$ & & & & & \\
\hline ECATS & $\mathrm{x}$ & & & & & & & \\
\hline burn-fair & $\mathrm{x}$ & & & & & $\mathrm{x}$ & & \\
\hline aireg & & \multicolumn{7}{|c|}{ renewable fuels } \\
\hline
\end{tabular}

Table 2: Selected properties of existing and potential aviation fuels [15]: hex: 1-hexanol; nc: naphthenic cut

\begin{tabular}{|c|c|c|c|c|c|}
\hline Fuel & \begin{tabular}{|l} 
Density \\
$/ \mathrm{kg} \mathrm{m}^{-3}$ \\
@ $15^{\circ} \mathrm{C}$
\end{tabular} & $\begin{array}{c}\text { Flashpoint } \\
{ }^{\circ} \mathbf{C}\end{array}$ & \begin{tabular}{|c} 
Heating \\
value \\
$/ \mathrm{kJ} \mathrm{kg}^{-1}$
\end{tabular} & $\begin{array}{c}\text { Viscosity } \\
\text { / cSto } \\
\text { @ - } 40 \text { C }\end{array}$ & $\begin{array}{l}\mathbf{C} / \mathbf{H} / \mathbf{O} \\
\text { / mass\% }\end{array}$ \\
\hline $\mathrm{CtL}$ & 816 & 57.5 & 42997 & 1.421 & $\begin{array}{c}85.9 \\
13.0 \\
0\end{array}$ \\
\hline GtL & 738 & 48.5 & 43242 & 0.8296 & $\begin{array}{c}85.8 \\
14.8 \\
0.0 \\
\end{array}$ \\
\hline $\begin{array}{c}\text { GtL } \\
+20 \% \text { hex }\end{array}$ & 754 & 46.5 & 42559 & 1.026 & $\begin{array}{c}82.5 \\
14.1 \\
3.6 \\
\end{array}$ \\
\hline $\begin{array}{c}\mathrm{GtL} \\
+50 \% \text { nc }\end{array}$ & 800 & 57.0 & 43373 & 1.415 & $\begin{array}{c}86.8 \\
13.6 \\
0.0\end{array}$ \\
\hline Jet A-1 & $775-840$ & $\begin{array}{c}38.0 \\
\text { minimum }\end{array}$ & $\begin{array}{c}42800 \\
\text { minimum }\end{array}$ & $\begin{array}{c}0.80-0.88 \\
\text { @ }-20^{\circ} \mathrm{C}\end{array}$ & $\begin{array}{c}\mathrm{C}+\mathrm{H} \\
>99 \\
0.0\end{array}$ \\
\hline
\end{tabular}

Table 3: Surrogates used for synthetic fuel air mixture

\begin{tabular}{|c|c|c|}
\hline \multirow{2}{*}{$\begin{array}{c}\text { Fuel } \\
\text { (measured) }\end{array}$} & \multicolumn{2}{|c|}{ Surrogate (modelling) } \\
\cline { 2 - 3 } & Species & $\begin{array}{c}\text { Percentage/ } \\
\text { mol\% }\end{array}$ \\
\hline FT-SPK (GtL) & $n$-decane & 57.7 \\
& iso-octane & 33.2 \\
& $n$-propylcyclohexane & 9.1 \\
\hline FT-SPK (GtL) & $n$-decane & 42.5 \\
+ & iso-octane & 24.4 \\
20\% 1-hexanol & $n$-propylcyclohexane & 6.7 \\
& 1-hexanol & 26.3 \\
\hline FT-SPK (GtL) & $n$-decane & 24.5 \\
+ & iso-octane & 21.0 \\
50\% naphthenic cut & $n$-propylcyclohexane & 54.5 \\
\hline FSJF (CtL) & $n$-decane & 39.5 \\
& iso-octane & 13.0 \\
& $n$-propylbenzene & 10.2 \\
& $n$-propylcyclohexane & 37.3 \\
\hline
\end{tabular}


The composition of the surrogates used for modeling the combustion of the re-formulated alternative aviation fuel mixtures considered within the present work are given in Tab. 3. The surrogate mixture derives from chemical composition of the fuel (determined by GC analyses) [15, 22, 44-45, 47].

\subsection{Characterization of burning velocity}

The burning velocities of the vaporized liquid synthetic fuel air mixtures are determined in a bunsen-type flame applying the cone angle method (Fig. 7); for details, see [22, 34-36, 44-45]. The experimental test rig consists of the burner housing with the flame holder, mass flow controllers for regulating fuel and air flows, a preevaporator, the pressure control system (by throttling exhaust gas flow), temperature controllers, and the ignition system. Conical shaped flames are stabilized above nozzle flame holders. The temperature of the flame holder is controlled in order to preheat the unburnt air/fuel-mixture to the value required.

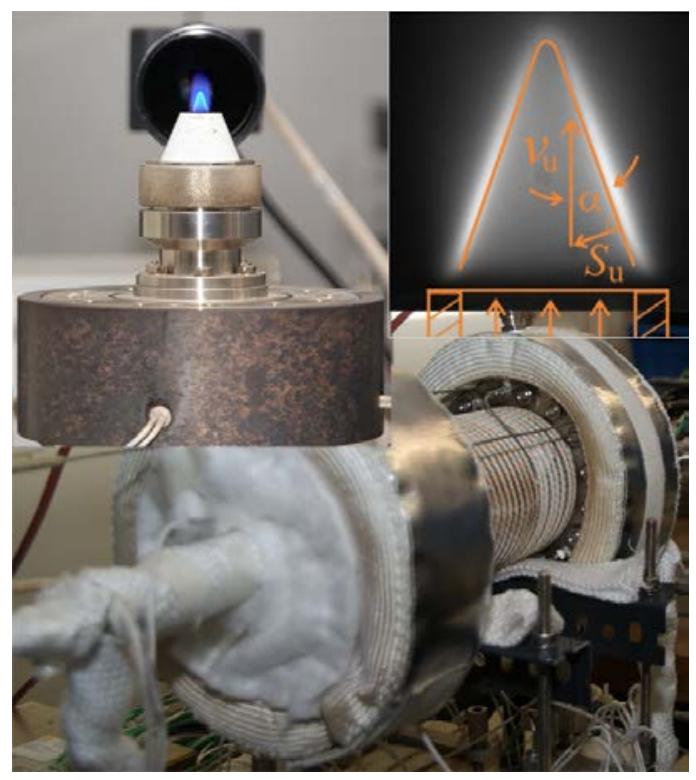

Fig. 7: The burner with a pre-evaporizer for determining the burning velocity of liquid fuels applying the cone angle method

The burning velocities of the fuels investigated (Table 1) are determined at ambient and elevated pressure (3 bar, for GtL) for equivalence ratios $\varphi$ between about 0.97 and 1.50 . The velocities are mostly studied at a preheat temperature $T_{0}=473 \mathrm{~K}$. The range of equivalence ratios is defined by the stabilization limits of the flame at the test-rig as reliable values for the burning velocity of a certain fuel-air mixture can be determined only from flames of the appropriate conical shape (Fig. 8). For comparison, data points for Jet A-1 measured at ambient pressure at the same experimental test rig [16] are also included in Fig. 8. Only a small deviation can be seen between Jet A-1 and re-formulated alternative aviation fuel (see e.g. CtL), within the uncertainty range. This comparison to Jet A-1 clearly shows the suitability of the fuels investigated defining the burning velocity as a measure for the heat release.

Predicted flame speeds values are slightly smaller for lean mixtures whereas the values are larger in the fuel rich region. In general, the agreement between predicted and measured data is good, for the GtL / air mixtures, and reasonable for CtL, respectively [15, 22, 34-36, 44-45]. The predicted and experimental data show the major expected trends as a function of equivalence ratio and pressure: (i) the maximum of the burning velocities is observed in the slightly fuel-rich regime and (ii) the higher the pressure, the lower the burning velocities.

Sensitivity analysis performed previously [22] has shown clearly that $n$-decane, the major component by far, is determining the overall oxidation of all alternative fuels studied. Thus, GtL and CtL mixtures have similar laminar flame speed values.

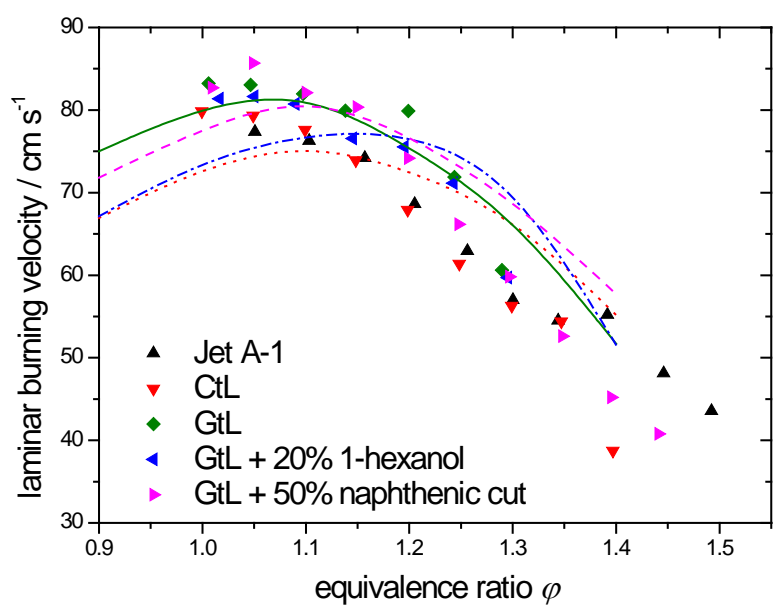

Fig. 8: Comparison between measured (symbols) and predicted (curves) laminar flame speed of reformulated alternative fuel-air-mixtures investigated within ALFABIRD [15]: $p=1$ bar and $T_{0}=473 \mathrm{~K}$. Data for Jet A-1 measured within SWAFEA [16] shown also

Calculations of laminar flame speeds of the surrogate components, performed at the same parameters as for the alternative fuels [22], provide valuable information on the further development of the chemical kinetic surrogate model of alternative fuels. For example, these calculations suggest the investigation of the sub-model describing the combustion of $n$-propylcyclohexane, because its maximum laminar flame speed value predicted peak around $\varphi=1.3$, and not around $\varphi=1.1$.

\subsection{Characterization of ignition delay time}

The ignition delay times of the reformulated fuels are determined applying the shock wave technique which allows to study the reaction progress under very precise conditions, at high temperatures and at high pressures 
simultaneously [48].

Details of the heated high pressure shock tube (see Fig. 9), the mixing procedure, the detection method as well as the evaluation of the measured ignition delay time data are given in $[44-45,48]$. The shock tube having an internal diameter of $46.0 \mathrm{~mm}$ is divided by aluminium diaphragms into a driver section and a driven section. The driven section is heated to $433 \mathrm{~K}$ and pumped down to pressures below $10^{-4} \mathrm{mbar}$ by a turbomolecular pump. The driver gas consisting of He (helium) and Ar (argon) is mixed with two Bronckhorst ${ }^{\circledR}$ mass flow controllers. The $\mathrm{He} / \mathrm{Ar}$ ratio is adapted depending on the temperature of the experiment as tailored conditions allow longer measurement times [48]. The temperature and pressure behind the reflected shock wave are computed from the measured incident shock speed and the speed attenuation. The estimated uncertainty in reflected shock temperature is less than $\pm 15 \mathrm{~K}$.

The ignition is observed by measuring pressure profiles and the $\mathrm{CH}^{*}$-emission at $431 \mathrm{~nm}$ selected by a narrow band pass filter (FWHM full width half maximum $=5 \mathrm{~nm}$ ) located at $1 \mathrm{~cm}$ distance from the end flange. All ignition delay time values shown here are determined by measuring the time difference between the initiation of the system by the reflected shock wave and the occurrence of the $\mathrm{CH}^{*}$-concentration maximum.

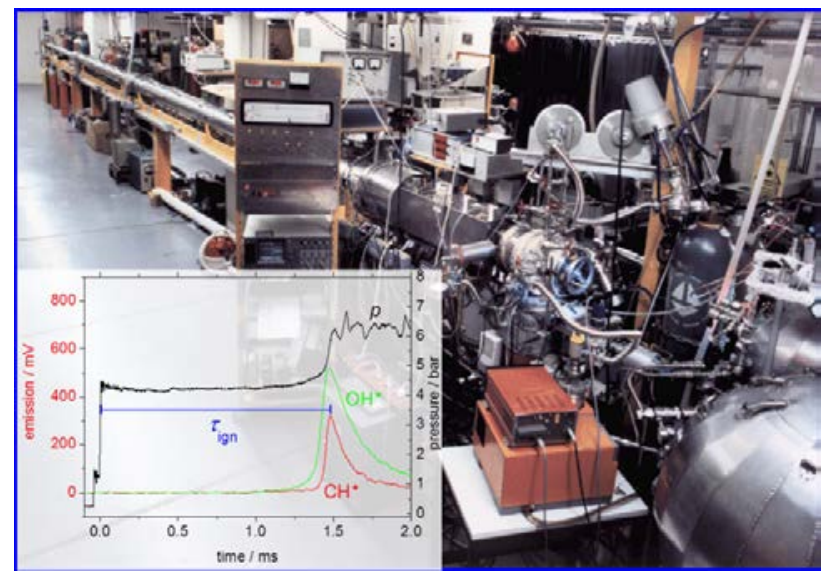

Fig. 9: The high pressure shock tube

The ignition delay times of the four ALFA-BIRD fuels as well as of Jet A-1 are measured at practical relevant conditions - elevated pressures around 16 bar, fuel-lean $(\varphi$ $=0.5)$ and stoichiometric $(\varphi=1.0)$ conditions, for temperatures between 850 - $1450 \mathrm{~K}$. A dilution of 1:2 (50 vol\% of the lean or stoichiometric mixture in synthetic air (80 vol\% $\mathrm{N}_{2}$ and 20 vol\% $\mathrm{O}_{2}$ ) / $50 \mathrm{vol} \% \mathrm{~N}_{2}$ ) was used.

In general, for the four synthetic jet fuel air mixtures investigated, predicted ignition delay times are longer than the measured ones: the lower the temperature, the more, by up to a factor of 2 at the lowest temperature studied.

As an example, the comparison of predicted (curves) and measured (symbols) ignition delay times of CtL-air mixtures is given in Fig. 10, together with data obtained for Jet A-, for fuel-lean $(\varphi=0.5)$ conditions. The measured ignition delay times for CtL and Jet A-1 are almost identical. Further studies of the ignition delay time have shown the importance of the $n$-alkane sub-model used; the addition of iso-alkanes, naphthenes, and aromatics is only of minor influence [44].

The investigation shows that, in the parameter range studied, the ignition delay time characteristics of the synthetic fuels studied are very similar to Jet A-1, although flight gas turbines operate at higher pressures [47]. Thus, concerning ignition delay, the chemical behavior of synthetic and standard kerosene might be described by a single surrogate and reaction model.

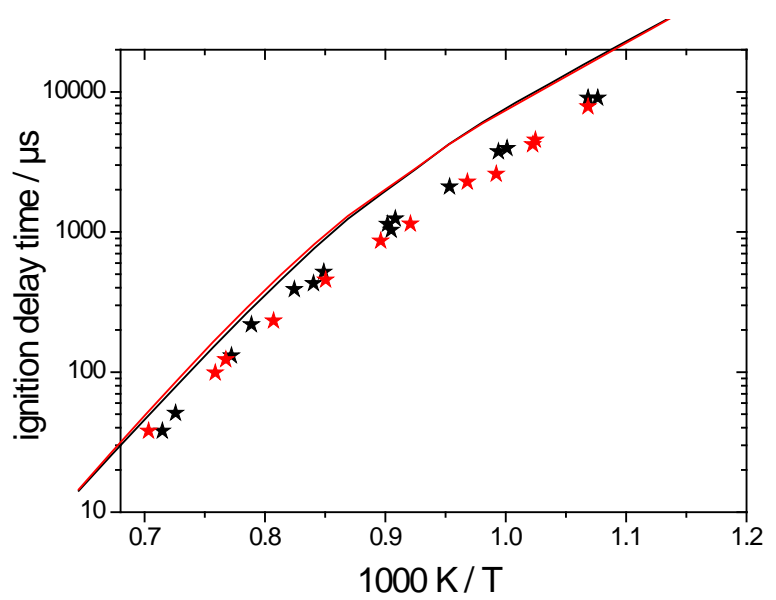

Fig. 10: Measured (symbols) and predicted (curves) ignition delay times of CtL (red) and Jet A-1 (black) at lean $(\varphi=0.5)$ conditions, pressures of about 16 bar, dilution 1:2 in $\mathrm{N}_{2}$

\section{$4 \quad$ Summary and conclusions}

An overview on major initiatives and current existing and possible alternative aviation jet fuels was presented focusing on technical suitability. Relevant international projects were summarized, in particular the European initiatives ALFA-BIRD [15] dedicated to the selection and the evaluation of the most promising alternative fuels with short to long-term perspective and SWAFEA [16] providing recommendations and a roadmap to policy makers. Furthermore, the German project burn-FAIR was discussed because this project was covering issues related to long-term effects due to the 1187 regular flights between Hamburg and Frankfurt, with 50 \% biofuel in one of the two engines of an airbus A321. Within burn-FAIR, it was proven that the bio-fuel used was as least as good as kerosene from crude oil concerning the emissions (CO, $\mathrm{CO}_{2}$, unburned hydrocarbons, particles, and soot).

Examples of the investigation of the technical suitability of two selected alternative aviation fuels (GtL, $\mathrm{CtL}$ ) and two re-formulated GtL mixtures (addition of 20\% 1-hexanol and 50\% naphthenic cut, respectively) were given for the measurement and prediction of two 
major combustion properties (burning velocity and ignition delay time) in a relevant parameter range.

To address two major combustion properties, data for the burning velocities were obtained nearly exclusively at ambient pressure, except for GtL (3 bar), for a preheat temperature of $473 \mathrm{~K}$ and equivalence ratios $\varphi$ ranging from about 0.95 to 1.5 . The ignition delay times were measured at practically relevant conditions - elevated pressures around $16 \mathrm{bar}$; fuel-lean $(\varphi=0.5)$ and stoichiometric $(\varphi=1.0)$ conditions, at a dilution 1:2 at temperatures ranging between 850 and $1500 \mathrm{~K}$. Data obtained for the reformulated fuels were compared to the ones of Jet A-1, if possible.

The burning velocities of GtL and CtL measured agree with each other, within the uncertainty range. The ignition delay times measured for the four fuel-air-mixtures discussed and Jet A-1 are almost identical. Also, within the parameter range studied, the data for burning velocity and ignition delay time experimentally determined agree with data obtained earlier for crude-oil based kerosene.

The experimental data served as a sound data base for validation of a detailed chemical kinetic reaction model. The predictive capability of the detailed reaction model used was demonstrated, with respect to laminar flame speeds and ignition delay time, for the parameter range considered. In general, good agreement was found between measured and calculated data. Also, the trends and main features were captured by the predictions.

Concerning laminar flame speed, for ambient pressure, in general, a reasonable, sometimes good (GtL) agreement was found between burning velocities measured and flame speeds predicted for all four fuels studied. At elevated pressure, the data predicted and experimentally observed differ more. For ignition delay times, a reasonable (CtL), almost good agreement between measurement and prediction was found, with predictions up to a factor of 2 longer predicted, depending on temperature.

Therefore, the detailed reaction model used can serve as the base for developing a reduced reaction model needed in numerical simulations of technical combustors, taking into account the interaction between turbulence and combustion. Thus, a better understanding of the combustion process and how to modify the design of the combustor when burning synthetic fuels may be achieved.

Our findings support the potential of those $\mathrm{CtL}$ and GtL mixtures investigated to serve as an alternative aviation fuel. The results of the present study will contribute to optimize synthetic jet fuel mixtures for practical combustors.

However, much work is still ahead, with the lack of availability of alternative fuels, in particular biofuels, in sufficient amounts and to be proven sustainable and economic viable. Also, experiments and modelling are needed covering all aspects of the effect of alternative fuels - from the impact of the fuel's composition on the combustion and emissions, from the combustor performance, including pre-evaporation of the liquid, and engine tests, among others [15-16, 22-23, 26, 40, 43]. Furthermore, research is needed to address durability and long-term effects, beyond to the approval process which is based on engine tests performed in a fixed short period. In addition, the issue of quality assurance over the entire fuel supply chain has to be investigated in more detail.

Acknowledgements The financial support of the European Commission (ALFA-BIRD [15], SWAFEA [16]), the BMWi Federal Ministry for Economic Affairs and Energy, Germany (burn-FAIR) [18], and of the Qatar Science and Technology Park (QSTP 19]) as well as the contribution from the project partners is gratefully acknowledged. The authors thank P. Le Clercq for fruitful discussions, J. Herzler and C. Naumann for their investigations on ignition delay times, Th. Kick and $\mathrm{T}$. Kathrotia for their work on burning velocities, and C. Wahl and M. Kapernaum for their analysis of the fuel compositions.

\section{References}

[1] U.S. Energy Information Administration (EIA) in: The International Energy Outlook, Washington, D.C. (USA), http://www.eia.gov/ (2011).

[2] Dagaut P., Cathonnet M.: The ignition, oxidation, and combustion of kerosene: A review of experimental and kinetic modeling. Prog. Energ. Combust. 32, 48-92 (2006).

[3] Hileman J.I., Stratton R.W., Donohoo P.E.: Energy Content and Alternative Jet Fuel Viability. J. Propul. Power 26, 184-95 (2010).

[4] M. Unnikrishnan, http://groups.yahoo.com/group/energyresources/message/1 09085 http://www.aviationweek.com (2007).

[5] International Air Transport Association (IATA) http://www.iata.org/pressroom/facts figures/fact sheets/Pa ges/environment.aspx (2011).

[6] Intergovernmental Panel on Climate Change (IPPC), Fourth Assessment Report, "Climate Change 2007: Mitigation of Climate Change", (2007).

http://www.ipcc.ch/publications_and_data/publications_ipc c fourth assessment report wg3 report mitigation of cli mate_change.htm

[7] Advisory Council on Aeronautics Research in Europe (ACARE), “Addendum to the strategic research agenda”, http://www.acare4europe.com/docs/ACARE_2008_Adden dum.pdf; (2008).

[8] Steele P., on behalf of ACI, CANSO, ICAO GIACC/3 IATA, ICCAIA, Montreal (Canada), http://www.icao.int/environmental-protection/GIACC/Giac c-3/Giacc3 Pres IndustryGoals.pdf (2009).

[9] IEA World Energy Outlook 2011, OECD/IEA, Paris (France), www.worldenergyoutlook.org (2011).

[10] International Air Transport Association, http://www.iata.org/whatwedo/Documents/economics/Indu stry-Outlook-Jun2012.pdf .

[11] http://www.aireg.de .

[12] World Resources Institute, "Beginner's Guide to Aviation Biofuels”. IATA, May 2009; http://www.enviro.aero/ .

[13] http://www.caafi.org/.

[14] EC, biofuels flight path: http://ec.europa.eu/energy/renewables/biofuels/doc/201106 22 biofuels flight path technical paper.pdf (2011).

[15] ALFA-BIRD: Alternative Fuels and Biofuels for Aircraft, EUFP7/2007-2013, grant agreement no ${ }^{\circ}$ 213266; http://www.alfa-bird.eu-vri.eu . 
[16] SWAFEA: Sustainable Way for Alternative Fuels and Energy for Aviation, EU, DG-TREN, http://www.swafea.eu/ .

[17] ASTM Standard D1655, www.astm.org .

[18] burn-FAIR, $\quad$ LuFO-IV project, http://presse.lufthansa.com/en/newsreleases/singleview/archive/2010/november/29/article/1828 html (2011).

[19] QSTP, Qatar Science and Technology Park, http://www.shell.com.qa/home/content/qat/products_servic es/qatartechnology/jet_fuel/.

[20] http://www.dstan.mod.uk/.

[21] Braun-Unkhoff M., Le Clercq P., Aigner M.: Alternative Fuels and Biofuels for Aircraft Development. Proc. of 17th European Biomass Conference and Exhibition, Hamburg, Germany (2009).

[22] Kick Th., Herbst J., Kathrotia T., Marquetand, J. BraunUnkhoff M., Naumann C., Riedel U.: An Experimental and Modeling Study of Burning Velocities of Possible Future Synthetic Jet Fuels. Energy 43(1), 111-123 (2012).

[23] Blakey S., Rye L., Wilson C.W.: Aviation gas turbine alternative fuels: A review. Proc. Combust. Inst. 33, 286385 (2011)

[24] http://www.nesteoil.com/default.asp?path=1,41,11991,122 43,17555, Neste Oil.

[25] http://www.uop.com/honeywells-uop-renewable-jet-fueltechnology-military-testing-certification/, UOP Honeywell.

[26] Moses C.A., Roets P.N.J.: An experimental and modelling study on the auto ignition of kerosene and surrogate fuel mixture. GT2008-50545, Proc. ASME Turbo Expo 2008: Power for Land, Sea and Air, Berlin (Germany), (2008).

[27] First commercial scheduled flight with GTL, October (2009); see e.g. http://www.shell.com.qa/en/aboutshell/media-centre/newsand-media-releases/archive/2009/commercial-passengerflight-naturalgas-land-121009.html

[28] Wahl, C. DLR, Institute of Combustion Technology, Stuttgart, Germany

[29] Steil U., Braun-Unkhoff M., Frank P., Aigner M.: An experimental and modelling study on the auto ignition of kerosene and surrogate fuel mixture. AIAA-2008-0973, Proc. 46th AIAA Aerospace Sciences Meeting and Exhibit. (2008).

[30] Beyersdorf A., Anderson B., Proc. 2nd Internat. Conference on Transport, Atmosphere and Climate (TAC-2), Aachen, Germany, and Maastricht, The Netherlands, 22-25 June (2009).

[31] Srinivasan A., Ellis B., Crittenden J.F., Lear W.E., Rotavera B., Petersen E.L.: Fischer-Tropsch fuel characterization via microturbine testing and fundamental combustion measurements. GT2008-51477. Proc. ASME Turbo Expo 2008, Berlin (Germany), (2008).

[32] DLR, Institute of Combustion Technology, ILA, Berlin air show, Berlin (Germany), (2010).

[33] Dagaut P.: On the kinetics of hydrocarbons oxidation from natural gas to kerosene and diesel fuel. Phys. Chem. Chem. Phys. No.4, 2079 -2094 (2002).

[34] Kick Th., Kathrotia T., Braun-Unkhoff M., Riedel U.: An Experimental and Modeling Study of Laminar Flame Speeds of Alternative Aviation Fuels. GT2011-45606, Proc. ASME Turbo Expo 2011, Vancouver (Canada), (2011).

[35] Kick Th., Kathrotia T., Braun-Unkhoff M., Herbst J., Naumann C., Riedel U.: An investigation of laminar flame speeds of alternative aviation fuel: An experimental and modeling study. Proc. 5th European Combustion Meeting; paper no. 269 (2011).

[36] Braun-Unkhoff M., Herbst J., Herzler J., Kathrotia T., Kick Th., Naumann C., Riedel U.: Alternative Fuels in Aviation. Proc. 20th European Biomass Conference, 1557- 1564, Milan (Italy) (2012).

[37] Slavinskaya N., Zizin A., Aigner M.: On surrogate fuel formulation. GT2009-60012, Proc. ASME Turbo Expo 2009, Orlando (USA), (2009).

[38] Slavinskaya N.: Skeletal mechanism for kerosene combustion with PAH production. Proc. 46th AIAA Aerospace Sciences Meeting and Exhibit, Reno (USA), Paper no. 0992 (2008).

[39] Slavinskaya N., Riedel U., Saibov E., Kunnaiyan K.: Surrogate Model Design for GTL Kerosene. Proc. 50th AIAA Aerospace Sciences Meeting and Exhibit, 09.12.01.2012, Nashville (USA) (2012).

[40] Vukadinovic V., Habisreuther P., Zarzalis N.: Experimental study on combustion characteristics of conventional and alternative liquid fuels. GT2012-69449, Proc. ASME Turbo Expo, Copenhagen (Denmark) (2012).

[41] Wahl C., Kapernaum M., Rindlisbacher T., Hjelmberg L.: Comparison of Nanoparticle Formation caused by leaded and unleaded Aviation Gasoline Combustion. 11th ETHConference on Combustion Generated Nanoparticles, August 13th -15th (Switzerland) (2007).

[42] Wahl C., Aigner M.: Aircraft Gas Turbine Soot Emission Tests under Technical Relevant Conditions in an Altitude Test Facility. GT2003-38797, Proc. ASME Turbo Expo 2003, Atlanta, (USA), (2003).

[43] Le Clercq P., Aigner M.: Impact of Alternative Fuels Physical Properties on Combustor Performance. ICLASS 2009, 11th Triennial Internat.ional Annual Conference on Liquid Atomization and Spray Systems, Vail, Colorado (USA), (2009).

[44] Mzé Ahmed A., Dagaut P., Hadj-Ali K., Dayma G., Kick Th., Herbst J., Kathrotia T., Braun-Unkhoff M., Herzler J., Naumann C., Riedel U.: The oxidation of a Coal-to-Liquid synthetic jet fuel: experimental and chemical kinetic modeling study. Energy Fuels 26 (10) 6070-6079, (2012).

[45] Dagaut P., Karsenty F., Dayma G., Diévart P., Hadj-Ali K., Mzé-Ahmed A., Braun-Unkhoff M., Herzler J., Kathrotia T., Kick Th., Naumann C., Riedel U., Thomas L.: Experimental and detailed kinetic model for the oxidation of a Gas to Liquid (GtL) jet fuel. Combust. Flame, 161(3) 835-847 (2014.

[46] Mze-Ahmed A., Hadj-Ali K., Dievart P., Dagaut P.: Kinetics of Oxidation of a Synthetic Jet Fuel in a JetStirred Reactor: Experimental and Modeling Study. Energy Fuel 24, 4904-11 (2010).

[47] Wahl C., Kapernaum M., Lützow M., ALFA-BIRD - DLR Stuttgart (2010).

[48] Herzler J., Naumann C.: Shock-tube study of the ignition of methane/ethane/hydrogen mixtures with hydrogen contents from $0 \%$ to $100 \%$ at different pressures. Proc. Combust. Inst. 32, 213-220 (2009).

[49] Gas turbine combustion, 2nd edition, Ed. H. Lefebvre, Taylor and Francis, ISBN 1-56032-675-5. 